\title{
Rastreabilidade da farinha de carne e ossos bovinos em ovos de poedeiras alimentadas com ingredientes alternativos
}

\author{
Juliana Célia Denadai(1), Carlos Ducatti(2), José Roberto Sartori(1), Antonio Celso Pezzato(1), Cleusa Móri(2), \\ Rosana Gottmann ${ }^{(1)}$ e Mariela Akie Okino Mituo(1)
}

\begin{abstract}
(1)Universidade Estadual Paulista (Unesp), Faculdade de Medicina Veterinária e Zootecnia, Departamento de Melhoramento Zootécnico e Nutrição Animal, Distrito de Rubião Júnior, s/no, Caixa Postal 510, CEP 18618-000 Botucatu, SP. E-mail: denadaijc@gmail.com, jrsartori@fca.unesp.br, cpezzato@fca.unesp.br, rosanagtt@yahoo.com.br, mariela_okino@yahoo.com.br (2)Unesp, Instituto de Biociências, Centro de Isótopos Estáveis. E-mail: ducatti@ibb.unesp.br, cleusamori@uol.com.br
\end{abstract}

Resumo - O objetivo deste trabalho foi detectar traços de farinha de carne e ossos bovinos, em ovos de poedeiras alimentadas com dietas comerciais com inclusão de ingredientes vegetais alternativos e leveduras. A detecção foi feita pela técnica dos isótopos estáveis do carbono e do nitrogênio. Foram utilizadas 384 poedeiras, distribuídas aleatoriamente em oito tratamentos. Os tratamentos consistiram de uma dieta-controle - à base de milho e farelo de soja - e sete dietas com inclusão de farinha de carne e ossos bovinos, acrescidas ou não de outros ingredientes (farelo de trigo, quirera de arroz, farelo de algodão, glúten de milho, levedura de cana e levedura de cerveja). No 35 dia, foram tomados aleatoriamente 24 ovos por tratamento: 12 para análise de ovo e 12 para análise de gema e albúmen, em separado. Após análise isotópica de carbono e nitrogênio, os resultados foram submetidos à análise multivariada de variância. As médias dos pares isotópicos dos ovos, gema e albúmen, em todos os tratamentos, diferiram daquelas do tratamento-controle. A técnica dos isótopos estáveis permite detectar, nos ovos, gema e albúmen, a farinha de carne e ossos bovinos utilizada na dieta de poedeiras, mesmo com a inclusão de outros ingredientes vegetais e leveduras.

Termos para indexação: Gallus gallus, carbono-13, certificação, encefalopatia espongiforme bovina, isótopos estáveis, nitrogênio-15.

\section{Traceability of bovine meat and bone meal in eggs from laying hens fed with alternative ingredients}

\begin{abstract}
The objective of this work was to detect traces of the bovine meat and bones meal in eggs of laying hens fed on commercial diets including alternative plant ingredients and yeast. The bovine meal detection was performed through carbon and nitrogen stable isotope technique. Three hundred eighty-four laying hens were randomly distributed in eight treatments. Treatments consisted of one control diet - a corn-and-soybean based meal - and seven diets with bovine meat and bone meal, including or not other ingredients (wheat bran, rice, cottonseed meal, corn gluten meal, sugarcane yeast and brewer yeast). At the $35^{\text {th }}$ day, 24 eggs per treatment were randomly collected, 12 for egg analyses and 12 for yolk and albumen analyses. After isotopic analysis of carbon and nitrogen, the results were submitted to multivariate analysis of variance. The average isotopic pairs of egg, yolk and albumen of all treatments differed from those of the control. The stable isotope technique allowed detection of bovine meat and bone meal in eggs, yolk and albumen, produced by laying hens fed on diets with inclusion of plant ingredients and yeast.
\end{abstract}

Index terms: Gallus gallus, carbon-13, certification, bovine spongiform encephalopathy, stable isotopes, nitrogen-15.

\section{Introdução}

O aumento do volume de exportação de produtos de aves do Brasil ocorreu a partir de 2006, em razão da descoberta de ocorrência de encefalopatia espongiforme bovina (EEB ou mal da vaca louca) nos Estados Unidos. A tendência do mercado mundial tem sido a de substituir a carne vermelha por frango, carne suína, peixes e ovos (Gomes, 2006). As exportações brasileiras de ovos em casca passaram de US\$ 300 mil, em janeiro de 2007, para US\$1,7 milhão, em dezembro de 2007. As vendas de produtos processados de ovos vêm se mantendo estáveis, porém o segmento está se estruturando para buscar outros mercados, como a União Européia. A expectativa é de manutenção da oferta de ovos comerciais ao mercado. Com o aumento 
nas exportações, espera-se equilíbrio nos volumes ofertados para o mercado interno e um possível aumento dos preços médios praticados em 2007 (UBA, 2008).

Para que a avicultura brasileira se beneficie desse mercado, é necessário valorizar os produtos avícolas por meio de processos de controle de doenças, certificação e rastreabilidade, pois o interesse do consumidor em conhecer a origem e a qualidade do produto consumido torna-se cada vez maior. A avicultura brasileira ainda não dispõe de um sistema de certificação oficial, porém algumas ferramentas de gestão e controle de qualidade já são utilizadas, como a análise de perigo em pontos críticos de controle (APPCC) ou as boas práticas de fabricação (BPF) (Cerutti, 2002).

Além dessas ferramentas de gestão e controle de qualidade, é desejável que haja na indústria avícola análise de contra prova para auxiliar na comprovação da veracidade das informações constantes no histórico alimentar de lotes de produtos diferenciados (carne e ovos de aves alimentadas estritamente com ingredientes vegetais), para monitorar o processo de rastreabilidade e fornecer laudos técnicos para as auditorias, como instrumento de confiabilidade (Oliveira, 2005). Por isso, muitos métodos têm sido propostos para identificar a presença de subprodutos de origem animal em rações para animais, tais como: hibridização de DNA, "enzyme linked immuno sorbent assay" (Elisa) e "polymerase chain reaction" (PCR) (Bloch Junior, 2002).

Por esses métodos não se detectam os subprodutos de origem animal no produto final, ou seja, na carne e nos ovos. Porém, a espectrometria de massas, por meio da análise da razão isotópica do carbono $\left({ }^{13} \mathrm{C} /{ }^{12} \mathrm{C}\right)$, tem sido usada com sucesso para testar a autenticidade, a qualidade e a origem geográfica de vários produtos, tais como: sucos de frutas (Bricout \& Koziet, 1987; Koziet et al., 1993), vinhos (Martin et al., 1988), méis (Brookes et al., 1991; White et al., 1998) e produtos lácteos (Rossmann et al., 2000; Manca et al., 2001). A razão isotópica do carbono, em associação à do nitrogênio $\left({ }^{15} \mathrm{~N} /{ }^{14} \mathrm{~N}\right)$, permitiu a certificação da origem geográfica e tipos de alimentação de ovinos (Piasentier et al., 2003), a caracterização e diferenciação do regime dietético de suínos ibéricos (González-Martin et al., 1999) e a rastreabilidade de produtos de origem animal na dieta de frangos de corte (Oliveira, 2005; Carrijo et al., 2006; Gottmann et al., 2008) e de codornas (Móri et al., 2007), no produto final.
Por meio da análise, pela técnica de isótopos estáveis do carbono e do nitrogênio, do albúmen de ovos de galinhas poedeiras, alimentadas com milho e farelo de soja, Denadai (2008) detectou a inclusão de 1,5\% de farinha de carne e ossos bovinos na ração.

O objetivo deste trabalho foi detectar traços de farinha de carne e ossos bovinos, pela técnica dos isótopos estáveis do carbono e do nitrogênio, em ovos de poedeiras alimentadas com ingredientes vegetais alternativos e leveduras.

\section{Material e Métodos}

O estudo foi realizado na Universidade Estadual Paulista (Unesp), Campus de Botucatu, no setor de Avicultura, localizado na Fazenda Experimental Edgárdia, da Faculdade de Medicina Veterinária e Zootecnia, no período de 14 de setembro a 19 de outubro de 2006. Foram utilizadas 384 galinhas poedeiras da linhagem "Shaver White", com 73 semanas de idade, que não consumiram dietas com inclusão de farinhas de origem animal.

Durante 35 dias as poedeiras foram alimentadas com as dietas experimentais com a finalidade de substituir os carbonos e os nitrogênios dos ovos, pelos da nova dieta. O período experimental foi determinado levando-se em consideração a substituição total do carbono nos ovos, que, segundo Denadai et al. (2006), ocorre de 24,5 a 33,6 dias.

O delineamento experimental utilizado foi inteiramente casualizado, com oito tratamentos e seis repetições, considerando como repetição uma gaiola com oito aves. Os tratamentos foram: controle - dieta à base de milho e de farelo de soja; sete dietas com inclusão de 4,5\% de farinha de carne e ossos bovinos. Desses sete tratamentos, em um não foram incluídos ingredientes alternativos; nos outros tratamentos foram acrescentados os seguintes ingredientes: farelo de trigo, quirera de arroz, farelo de algodão, glúten de milho, levedura de cana-de-açúcar e levedura de cerveja.

Para a fixação da percentagem de inclusão da farinha de carne e ossos $(4,5 \%)$, foi levado em consideração o teor de fósforo fornecido pela farinha, em substituição total ao fosfato bicálcico. A inclusão dos outros ingredientes foi fixada com base na percentagem de participação ao farelo de trigo, ingrediente mais utilizado em dietas para aves de postura.

As dietas experimentais foram fornecidas em comedouros tipo calha independente, e a água foi 
fornecida em bebedouros lineares de água corrente, ambos localizados frontalmente à gaiola. Aágua e a ração foram fornecidas à vontade. O programa de iluminação artificial adotado foi de 16 horas de luz por dia.

As dietas foram formuladas para atender as exigências nutricionais das aves, estabelecidas por Rostagno et al. (2005), e balanceadas de modo que fossem isoenergéticas, isoprotéicas, isocálcicas, isofosfóricas e isoaminoacídicas para metionina + cistina e lisina (Tabela 1). Os ingredientes e as dietas foram analisados isotopicamente, em duplicata, para carbono e nitrogênio.

No $35^{\circ}$ dia foram coletados, aleatoriamente, 24 ovos por tratamento (quatro por repetição), dos quais 12 (dois por repetição) foram usados para coleta das amostras de gema e albúmen e os outros 12 (dois por repetição) para ovo (gema + albúmen). A gema e o albúmen foram separados manualmente e as amostras de ovo foram homogeneizadas em liquidificador. As amostras foram acondicionadas em sacos de plástico e congeladas a $-20^{\circ} \mathrm{C}$ para posteriores análises isotópicas no Centro de Isótopos Estáveis do Instituto de Biociências, da Unesp, Botucatu, SP.

$\mathrm{Na}$ ocasião das análises, as amostras foram descongeladas e secas em estufa de ventilação forçada (Marconi - modelo MA 035) a $56^{\circ} \mathrm{C}$, por 24 horas, para o albúmen e, por 48 horas, para o ovo e a gema. Após a secagem, as amostras foram moídas em moinho criogênico (Spex-6750 freezer/mill) a $-196^{\circ} \mathrm{C}$. Neste moinho, foram colocados aproximadamente $2 \mathrm{~g}$ de amostra em um frasco de policarbonato juntamente com a barra magnética, o qual foi fechado e imerso em nitrogênio líquido. Pelo impacto entre a amostra e a barra magnética, submetida a um campo magnético oscilante (15 impactos por segundo), pulverizou-se a amostra. O programa utilizado na moagem das amostras constituiu-se

Tabela 1. Composição percentual e nutricional das dietas experimentais de poedeiras.

\begin{tabular}{|c|c|c|c|c|c|c|c|c|}
\hline \multirow[t]{2}{*}{ Ingredientes (\%) } & \multicolumn{8}{|c|}{ Tratamento $^{(1)}$} \\
\hline & $\mathrm{CON}$ & FCO & TRI & ARR & ALG & GLU & CAN & CER \\
\hline Milho moído & 64,91 & 66,39 & 65,31 & 63,48 & 66,44 & 65,61 & 65,49 & 65,49 \\
\hline Farelo de soja & 22,72 & 18,34 & 17,44 & 18,33 & 16,21 & 14,36 & 16,33 & 16,33 \\
\hline Óleo de soja & 0,45 & - & - & - & - & - & - & - \\
\hline Farinha de carne e ossos & - & 4,50 & 4,50 & 4,50 & 4,50 & 4,50 & 4,50 & 4,50 \\
\hline Farelo de trigo & - & - & 3,00 & - & - & - & - & - \\
\hline Quirera de arroz & - & - & - & 3,00 & - & - & - & - \\
\hline Farelo de algodão & - & - & - & - & 3,00 & - & - & - \\
\hline Glúten de milho & - & - & - & - & - & 3,00 & - & - \\
\hline Levedura de cana-de-açúcar & - & - & - & - & - & - & 3,00 & - \\
\hline Levedura de cerveja & - & - & - & - & - & - & - & 3,00 \\
\hline Calcário calcítico & 9,71 & 9,00 & 9,00 & 9,00 & 8,99 & 9,00 & 9,00 & 9,00 \\
\hline Fosfato bicálcico & 1,51 & - & - & - & - & 0,05 & - & - \\
\hline DL-Metionina & 0,15 & 0,15 & 0,15 & 0,15 & 0,15 & 0,13 & 0,16 & 0,16 \\
\hline L-Lisina & - & 0,04 & 0,05 & 0,04 & 0,06 & 0,14 & 0,02 & 0,02 \\
\hline Sal comum & 0,35 & 0,35 & 0,35 & 0,35 & 0,35 & 0,35 & 0,35 & 0,35 \\
\hline Suplemento vitamínico ${ }^{(2)}$ & 0,10 & 0,10 & 0,10 & 0,10 & 0,10 & 0,10 & 0,10 & 0,10 \\
\hline Suplemento mineral ${ }^{(3)}$ & 0,10 & 0,10 & 0,10 & 0,10 & 0,10 & 0,10 & 0,10 & 0,10 \\
\hline Caulim & - & 1,03 & - & 0,95 & 0,10 & 2,66 & 0,95 & 0,95 \\
\hline Total & 100,00 & 100,00 & 100,00 & 100,00 & 100,00 & 100,00 & 100,00 & 100,00 \\
\hline \multicolumn{9}{|c|}{ Composição nutricional calculada } \\
\hline EM $\left(\mathrm{kcal} \mathrm{kg}^{-1}\right)^{(4)}$ & 2.750 & 2.750 & 2.750 & 2.750 & 2.750 & 2.750 & 2.750 & 2.750 \\
\hline PB $(\%)^{(5)}$ & 16,00 & 16,00 & 16,00 & 16,00 & 16,00 & 16,00 & 16,00 & 16,10 \\
\hline Cálcio total (\%) & 4,05 & 4,05 & 4,05 & 4,05 & 4,05 & 4,05 & 4,05 & 4,05 \\
\hline Fósforo disponível (\%) & 0,37 & 0,37 & 0,37 & 0,37 & 0,37 & 0,37 & 0,37 & 0,37 \\
\hline Fibra bruta $(\%)$ & 2,61 & 2,44 & 2,63 & 2,39 & 3,07 & 2,22 & 2,32 & 2,32 \\
\hline Metionina $(\%)$ & 0,41 & 0,40 & 0,40 & 0,40 & 0,40 & 0,40 & 0,41 & 0,41 \\
\hline Aminoácidos sulfurados (\%) & 0,68 & 0,68 & 0,68 & 0,68 & 0,68 & 0,68 & 0,68 & 0,68 \\
\hline Lisina $(\%)$ & 0,79 & 0,79 & 0,79 & 0,79 & 0,79 & 0,79 & 0,79 & 0,79 \\
\hline
\end{tabular}

${ }^{(1)} \mathrm{CON}$, tratamento-controle; FCO, adição de farinha de carne e ossos bovinos; TRI, adição de farelo de trigo; ARR, adição de quirera de arroz; ALG, adição de farelo de algodão; GLU, adição de glúten de milho; CAN, adição de levedura de cana; CER, adição de levedura de cerveja. ${ }^{(2)}$ Suplemento vitamínico por quilograma de ração: vitamina $\mathrm{A}, 10.000 \mathrm{UI}$; vitamina $\mathrm{D}_{3}, 2.000 \mathrm{UI}$; vitamina $\mathrm{E}, 12,5 \mathrm{mg}$; vitamina $\mathrm{K}_{3}, 2,5 \mathrm{mg}$; vitamina $\mathrm{B}_{1}, 2,4 \mathrm{mg}$; vitamina $\mathrm{B}_{2}, 6 \mathrm{mg}$; vitamina $\mathrm{B}_{6}, 3,2 \mathrm{mg}$; vitamina $\mathrm{B}_{12}, 12 \mu \mathrm{g}$; ácido fólico, $1 \mathrm{mg}$; pantotenato de cálcio, $12,5 \mathrm{mg}$; niacina, $30 \mathrm{mg}$; antioxidante, $15 \mathrm{mg}$; selênio, $0,3 \mathrm{mg}$. ${ }^{(3)}$ Suplemento mineral por quilograma de ração: cobre, $12 \mathrm{mg}$; ferro, $50 \mathrm{mg}$; iodo, $1 \mathrm{mg}$; manganês, $65 \mathrm{mg}$; zinco, $50 \mathrm{mg}$. ${ }^{(4)} \mathrm{EM}$, energia metabolizável. ${ }^{(5)} \mathrm{PB}$, proteína bruta. 
de uma primeira etapa de pré-congelamento por $1 \mathrm{~min}$ e, uma segunda etapa, de congelamento e pulverização por $3 \mathrm{~min}$. Esse procedimento permite a obtenção de partículas com granulometria menor que $60 \mu \mathrm{m}$ (Licatti, 1997; Rosa, et al., 2002; Denadai, 2008).

Os lipídeos das amostras de ovo e gema foram extraídos porque esses são relativamente pobres em carbono-13, e a extração deles facilita a comparação entre tecidos e frações com proporções lipídicas distintas (tecidos e dietas) (Tieszen et al., 1983). As amostras foram acondicionadas em papelfiltro, imersas em éter etílico (p.a.) e mantidas em temperatura em torno de $60^{\circ} \mathrm{C}$, por 4 horas, por meio do aparelho de Soxhlet (TE-044). Após esse período, as amostras foram suspensas durante 1 hora para que apenas 0 éter recondicionado as lavasse. Posteriormente, as amostras foram retiradas do aparelho e secas em estufa de ventilação forçada durante uma hora, para que houvesse evaporação do éter, e foram novamente moídas para homogeneização.

As amostras moídas foram pesadas em cápsulas de estanho, sendo para ovo, gema e albúmen, de 50 a $60 \mu \mathrm{g}$ e 500 a $600 \mu \mathrm{g}$ e, para os ingredientes e ração, em duplicata, de 60 a $70 \mu \mathrm{g}$ e 1.600 a $1.700 \mu \mathrm{g}$ para determinação das razões isotópicas do carbono e do nitrogênio, respectivamente. As cápsulas foram introduzidas, por meio de amostrador automático, no analisador elementar (EA $1108-\mathrm{CHN}$ - Fisons Instruments), onde a amostra foi queimada para a obtenção de $\mathrm{CO}_{2}$ e $\mathrm{N}_{2}$. Os gases formados foram separados em coluna cromatográfica gasosa e analisados no espectrômetro de massas de razões isotópicas (Delta $\mathrm{S}$ - Finnigan MAT).

Os valores das razões isotópicas foram expressos em delta $(\delta)$ relativos aos padrões internacionais PeeDee Belemnite (PDB) para o ${ }^{13} \mathrm{C}$, e relativo ao nitrogênio atmosférico, para ${ }^{15} \mathrm{~N}$, de acordo com a equação geral: $\delta \mathrm{X}_{\text {(amostra, padrão) }}=1.000\left[\left(\mathrm{R}_{\text {amostra }}-\mathrm{R}_{\text {padrão }}\right) / \mathrm{R}_{\text {padrão }}\right]$, em que: $\delta \mathrm{X}$ representa o enriquecimento do isótopo pesado do elemento químico $\mathrm{X}\left({ }^{13} \mathrm{C}\right.$ ou $\left.{ }^{15} \mathrm{~N}\right)$ da amostra, em relação ao respectivo padrão internacional; $\mathrm{R}$ representa $\mathrm{a}$ razão entre o isótopo pesado e o leve, em particular ${ }^{13} \mathrm{C} /{ }^{12} \mathrm{C}$ e ${ }^{15} \mathrm{~N} /{ }^{14} \mathrm{~N}$.

Os resultados isotópicos obtidos foram submetidos à análise multivariada de variância (MANOVA), com auxílio do procedimento GLM do SAS (SAS Institute, 1996). A partir dos dados gerados pelas matrizes de erro, foram determinadas regiões com 95\% de confiança para verificar as diferenças entre as médias dos tratamentos que tiveram adição de farinha de carne e ossos e a média do grupo-controle (dieta estritamente vegetal).

\section{Resultados e Discussão}

Pelas análises isotópicas das rações utilizadas, houve enriquecimento nos valores de $\delta^{15} \mathrm{~N}$ e $\delta^{13} \mathrm{C}$, em decorrência da inclusão da farinha de carne e ossos bovinos nas dietas (Tabela 2). Oliveira (2005), Carrijo et al. (2006), Móri et al. (2007) e Gottmann et al. (2008) também observaram enriquecimento em ${ }^{13} \mathrm{C}$ e ${ }^{15} \mathrm{~N}$, em dietas de aves que continham farinha de origem animal.

Tabela 2. Médias \pm desvios-padrão de $\delta^{13} \mathrm{C}$ e $\delta^{15} \mathrm{~N}(\%)$ das dietas $(\mathrm{n}=2)$, ovos e suas frações $(\mathrm{n}=12)$, de poedeiras.

\begin{tabular}{|c|c|c|c|c|c|}
\hline Tratamento $^{(1)}$ & Variável & Dieta & Ovo & Albúmen & Gema \\
\hline \multirow[t]{2}{*}{$\overline{\mathrm{CON}}$} & $\delta^{13} \mathrm{C}$ & $-15,79 \pm 0,08$ & $-18,31 \pm 0,12$ & $-18,28 \pm 0,15$ & $-18,38 \pm 0,08$ \\
\hline & $\delta^{15} \mathrm{~N}$ & $1,53 \pm 0,03$ & $4,43 \pm 0,18$ & $3,47 \pm 0,15$ & $4,44 \pm 0,12$ \\
\hline \multirow[t]{2}{*}{$\mathrm{FCO}$} & $\delta^{13} \mathrm{C}$ & $-14,89 \pm 0,22$ & $-17,32 \pm 0,08$ & $-17,40 \pm 0,09$ & $-17,24 \pm 0,18$ \\
\hline & $\delta^{15} \mathrm{~N}$ & $2,36 \pm 0,11$ & $5,02 \pm 0,08$ & $4,09 \pm 0,05$ & $5,08 \pm 0,09$ \\
\hline \multirow[t]{2}{*}{ TRI } & $\delta^{13} \mathrm{C}$ & $-15,90 \pm 0,08$ & $-17,49 \pm 0,15$ & $-17,30 \pm 0,09$ & $-17,48 \pm 0,11$ \\
\hline & $\delta^{15} \mathrm{~N}$ & $2,39 \pm 0,09$ & $5,01 \pm 0,19$ & $4,67 \pm 0,16$ & $5,24 \pm 0,11$ \\
\hline \multirow[t]{2}{*}{ ARR } & $\delta^{13} \mathrm{C}$ & $-15,67 \pm 0,14$ & $-17,72 \pm 0,08$ & $-17,48 \pm 0,07$ & $-17,76 \pm 0,13$ \\
\hline & $\delta^{15} \mathrm{~N}$ & $2,49 \pm 0,08$ & $5,07 \pm 0,18$ & $4,81 \pm 0,17$ & $5,36 \pm 0,22$ \\
\hline \multirow[t]{2}{*}{ ALG } & $\delta^{13} \mathrm{C}$ & $-15,41 \pm 0,04$ & $-17,27 \pm 0,07$ & $-17,00 \pm 0,11$ & $-17,14 \pm 0,11$ \\
\hline & $\delta^{15} \mathrm{~N}$ & $2,45 \pm 0,03$ & $5,32 \pm 0,25$ & $4,77 \pm 0,12$ & $5,93 \pm 0,14$ \\
\hline \multirow[t]{2}{*}{ GLU } & $\delta^{13} \mathrm{C}$ & $-14,63 \pm 0,11$ & $-15,90 \pm 0,16$ & $-15,89 \pm 0,15$ & $-16,16 \pm 0,16$ \\
\hline & $\delta^{15} \mathrm{~N}$ & $2,82 \pm 0,08$ & $5,14 \pm 0,13$ & $4,93 \pm 0,08$ & $6,11 \pm 0,12$ \\
\hline \multirow[t]{2}{*}{ CAN } & $\delta^{13} \mathrm{C}$ & $-15,16 \pm 0,22$ & $-16,46 \pm 0,20$ & $-16,38 \pm 0,15$ & $-16,64 \pm 0,13$ \\
\hline & $\delta^{15} \mathrm{~N}$ & $2,57 \pm 0,09$ & $5,05 \pm 0,22$ & $4,18 \pm 0,09$ & $6,02 \pm 0,12$ \\
\hline \multirow[t]{2}{*}{ CER } & $\delta^{13} \mathrm{C}$ & $-15,28 \pm 0,08$ & $-16,60 \pm 0,18$ & $-16,66 \pm 0,14$ & $-16,82 \pm 0,12$ \\
\hline & $\delta^{15} \mathrm{~N}$ & $2,56 \pm 0,02$ & $5,19 \pm 0,12$ & $4,31 \pm 0,12$ & $6,10 \pm 0,21$ \\
\hline
\end{tabular}


Dos ingredientes utilizados, os mais ricos em ${ }^{13} \mathrm{C}$ foram levedura de cana, seguida pela farinha de carne e ossos e o milho, e o mais rico em ${ }^{15} \mathrm{~N}$ foi a farinha de carne e ossos. Os mais pobres, em ambos os isótopos, foram o óleo e o farelo de soja (Tabela 3). O enriquecimento isotópico das dietas ocorreu pela variação na composição percentual dos ingredientes (Handley \& Raven, 1992; Vogel, 1993; Werner \& Schimidt, 2002). O comportamento dessas variações nas dietas pôde ser observado no ovo e nas suas frações, visto que sua assinatura isotópica é refletida no organismo dos animais (DeNiro \& Epstein, 1981).

Os valores médios dos pares isotópicos das amostras, quando analisados estatisticamente, geraram regiões com 95\% de confiança (Figuras 1, 2 e 3). Para o ovo e suas frações, verificou-se que as médias dos pares isotópicos dos tratamentos com adição da farinha de carne e ossos diferiram da média do tratamentocontrole (ou estritamente vegetal), pois suas regiões de confiança não sobrepuseram nenhum dos eixos do gráfico (Figura 1).

No ovo as diferenças entre médias de $\delta^{15} \mathrm{~N}$ dos tratamentos com adição de farinha de carne e ossos foram semelhantes entre si, variando de 0,4 a 0,9 . O tratamento com adição de farelo de algodão apresentou maior enriquecimento e, consequentemente, maior diferença, de 0,7 a 1,1 (Figura 1).

Em relação ao ${ }^{13} \mathrm{C}$ das dietas com inclusão de ingredientes $\mathrm{C}_{3}$, o tratamento com adição de quirera de arroz apresentou menor enriquecimento (diferença entre médias do tratamento e controle variando de $0,4$ a 0,75$)$, e os tratamentos com adição de farelo de trigo e com adição de farelo de algodão apresentaram enriquecimento isotópico semelhante ao tratamento apenas com adição de farinha de carne e ossos (diferença entre médias dos tratamentos e controle de 0,68 a 1,2). O tratamento com adição de glúten de

Tabela 3. Médias \pm desvios-padrão de $\delta^{13} \mathrm{C}$ e $\delta^{15} \mathrm{~N}$ dos ingredientes $(\mathrm{n}=2)$ utilizados nas dietas experimentais.

\begin{tabular}{lcc}
\hline Ingrediente & $\delta^{13} \mathrm{C}$ & $\delta^{15} \mathrm{~N}$ \\
\hline Farinha de carne e ossos & $-12,82 \pm 0,13$ & $7,43 \pm 0,22$ \\
Milho moído & $-13,19 \pm 0,03$ & $3,57 \pm 0,23$ \\
Farelo de soja & $-26,57 \pm 0,35$ & $0,43 \pm 0,05$ \\
Farelo de trigo & $-26,65 \pm 0,08$ & $2,62 \pm 0,05$ \\
Farelo de algodão & $-27,15 \pm 0,11$ & $3,77 \pm 0,11$ \\
Quirera de arroz & $-28,97 \pm 0,61$ & $7,14 \pm 0,29$ \\
Glúten de milho & $-15,14 \pm 0,42$ & $3,68 \pm 0,01$ \\
Levedura de cana-de-açúcar & $-10,49 \pm 0,08$ & $3,18 \pm 0,01$ \\
Levedura de cerveja & $-16,76 \pm 0,06$ & $3,63 \pm 0,00$ \\
Óleo de soja & $-31,54 \pm 0,21$ & - \\
\hline
\end{tabular}

milho $\left(\mathrm{C}_{4},\right)$ apresentou maior enriquecimento entre os tratamentos experimentais. Os tratamentos com inclusão de levedura de cana-de-açúcar e de levedura de cerveja foram intermediários.

Para o albúmen o enriquecimento de ${ }^{15} \mathrm{~N}$ dos tratamentos com adição de farelo de trigo, quirera de arroz, glúten de milho e com adição de farelo de algodão foi maior quando comparado ao tratamento com adição de farinha de carne e ossos bovinos (Figura 2). Os tratamentos com inclusão de levedura de cana-de-açúcar e de levedura de cerveja seguiram a mesma tendência observada no ovo, com enriquecimento semelhante ao tratamento com adição de farinha de carne e ossos. Em relação ao ${ }^{13} \mathrm{C}$, os tratamentos com adição de farelo de trigo, quirera de arroz e farelo de algodão apresentaram enriquecimento isotópico semelhante ao tratamento com adição de farinha de carne e ossos. Já o tratamento com adição de glúten de milho, foi o que apresentou maior enriquecimento entre os tratamentos experimentais, e os tratamentos com inclusão de levedura de cana-de-açúcar e de levedura de cerveja foram intermediários.

As médias de ${ }^{15} \mathrm{~N}$ na gema de todos os tratamentos foram maiores em comparação ao tratamento com inclusão apenas de farinha de carne e ossos (Figura 3). Quando comparados ao tratamento com inclusão apenas de farinha de carne e ossos, o ${ }^{13} \mathrm{C}$ da dieta com adição de farelo de algodão foi semelhante, os tratamentos com adição de farelo de trigo e quirera de arroz tiveram empobrecimento

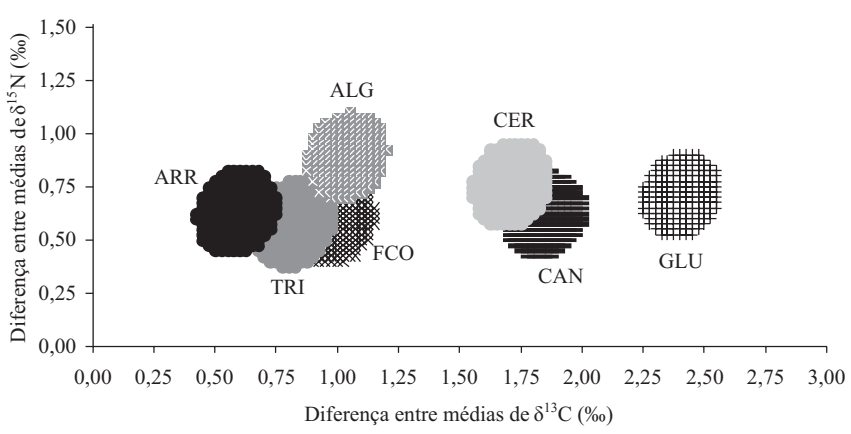

Figura 1. Regiões de confiança formadas pela diferença entre os valores isotópicos de $\delta^{13} \mathrm{C}$ e $\delta^{15} \mathrm{~N}$ dos ovos de poedeiras, de cada tratamento $(\mathrm{n}=12)$, quando comparados ao tratamento-controle (intersecção entre os eixos). FCO, adição de farinha de carne e ossos; TRI, adição de farelo de trigo; ARR, adição de quirera de arroz; ALG, adição de farelo de algodão; GLU, adição de glúten de milho; CAN, adição de levedura de cana; CER, adição de levedura de cerveja. 


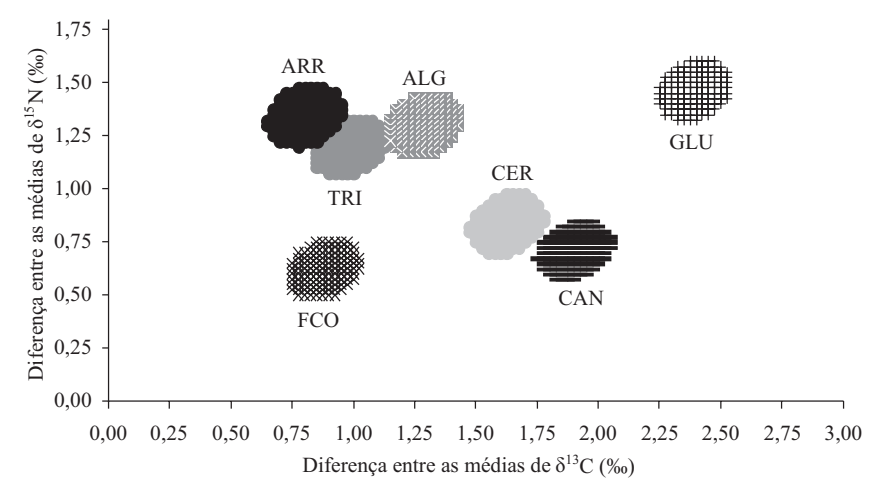

Figura 2. Regiões de confiança formadas pela diferença entre os valores isotópicos de $\delta^{13} \mathrm{C}$ e $\delta^{15} \mathrm{~N}$ do albúmen de poedeiras, de cada tratamento $(\mathrm{n}=12)$, quando comparados ao tratamento-controle (intersecção entre os eixos). FCO, adição de farinha de carne e ossos; TRI, adição de farelo de trigo; ARR, adição de quirera de arroz; ALG, adição de farelo de algodão; GLU, adição de glúten de milho; CAN, adição de levedura de cana-de-açúcar; CER, adição de levedura de cerveja.

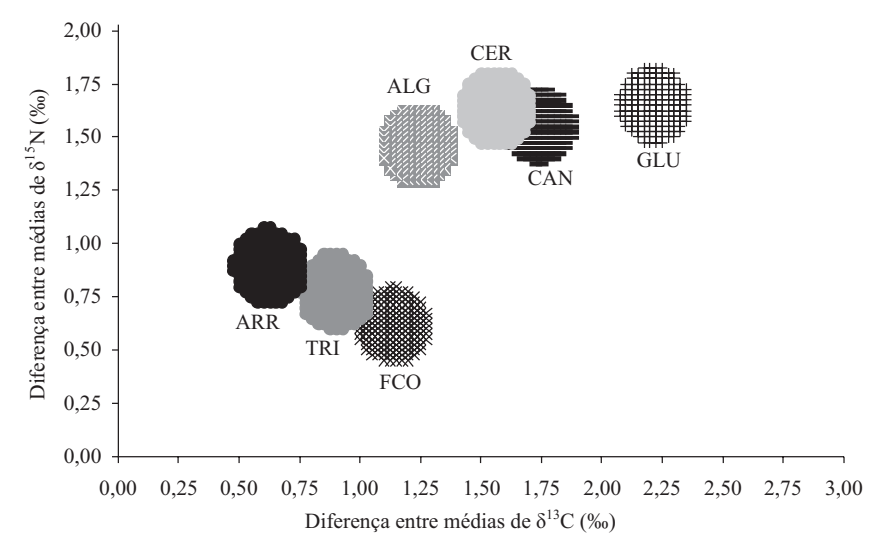

Figura 3. Regiões de confiança formadas pela diferença entre os valores isotópicos de $\delta^{13} \mathrm{C}$ e $\delta^{15} \mathrm{~N}$ da gema de poedeiras, de cada tratamento $(\mathrm{n}=12)$, quando comparados ao tratamentocontrole (intersecção entre os eixos). FCO, adição de farinha de carne e ossos; TRI, adição de farelo de trigo; ARR, adição de quirera de arroz; ALG, adição de farelo de algodão; GLU, adição de glúten de milho; CAN, adição de levedura de canade-açúcar; CER, adição de levedura de cerveja.

isotópico, e os tratamentos com adição de glúten de milho, levedura de cana-de-açúcar e levedura de cerveja apresentaram enriquecimento isotópico.

Mesmo com a inclusão de outros ingredientes (farelo de trigo, quirera de arroz, farelo de algodão, glúten de milho, levedura de cana-de-açúcar e levedura de cerveja), além daqueles utilizados na dieta- controle (milho e farelo de soja), foi possível detectar isotopicamente, no ovo e nas suas frações, a inclusão de farinha de carne e ossos na dieta de poedeiras. Esses dados concordam com Gottmann et al. (2008), que avaliou dietas com inclusão de farelo de trigo e/ou levedura de cana-de-açúcar, além de milho, farelo de soja, farinha de carne e ossos e farinha de vísceras de aves, para frangos de corte, e esses ingredientes também não interferiram na detecção dessa farinha. Essa técnica também possibilitou a certificação de origem geográfica e regime de alimentação em estudo com ovinos (Piasentier et al., 2003), e para caracterização do regime dietético de suínos, por meio de análises isotópicas conjuntas de carbono $\left(\delta^{13} \mathrm{C}\right)$ e enxofre $\left(\delta^{34} \mathrm{~S}\right)$ (Gonzáles-Martin et al., 2001).

\section{Conclusão}

A técnica dos isótopos estáveis do carbono e nitrogênio permite detectar em ovos e em suas frações (gema e albúmen) a farinha de carne e ossos bovinos utilizada na dieta de poedeiras, mesmo com a inclusão de outros ingredientes vegetais e leveduras.

\section{Agradecimentos}

À Fundação de Amparo à Pesquisa do Estado de São Paulo e ao Fundo para Desenvolvimento da Universidade Estadual Paulista, pelo apoio financeiro.

\section{Referências}

BLOCK JUNIOR, C. Monitoramento da qualidade de rações brasileiras para ruminantes por espectrometria de massa. In: SIMPÓSIO SOBRE MANEJO E NUTRIÇÃO DE AVES E SUÍNOS E TECNOLOGIA DA PRODUÇÃO DE RAÇÕES, 2002, Campinas. Anais. Campinas: Colégio Brasileiro de Nutrição Animal, 2002. p.251-252.

BRICOUT, J.; KOZIET, J. Control of the authenticity of orange juice by isotopic analysis. Journal of Agricultural Food Chemistry, v.35, p.758-760, 1987.

BROOKES, S.T.; BARRIE, A.; DAVIES, J.E. A rapid ${ }^{13} \mathrm{C} /{ }^{12} \mathrm{C}$ test for determination of corn-syrups in honey. Journal of the Association of Official Analytical Chemists, v.74, p.627-629, 1991.

CARRIJO, A.S.; PEZZATO, A.C.; DUCATTI, C.; SARTORI, J.R.; TRINCA, L.; SILVA, E.T. Traceability of bovine meat and bone meal in poultry by stable isotope analysis. Revista Brasileira de Ciência Avícola, v.8, p.37-42, 2006.

CERUTTI, M. Aplicação de um programa de rastreabilidade na cadeia de frangos de corte. In: SIMPÓSIO SOBRE MANEJO E NUTRIÇÃO DE AVES E SUÍNOS E TECNOLOGIA DA 
PRODUÇÃO DE RAÇÕES, 2002, Campinas. Anais. Campinas: Colégio Brasileiro de Nutrição Animal, 2002. p.253-264.

DENADAI, J.C. Rastreabilidade de farinhas de origem animal em ovos de poedeiras comerciais pela técnica dos isótopos estáveis do carbono $\left(\delta^{13} \mathbf{C}\right)$ e do nitrogênio $\left(\delta^{15} \mathbf{N}\right)$. 2008. 90p. Tese (Doutorado) - Universidade Estadual Paulista, Botucatu.

DENADAI, J.C.; DUCATTI, C.; PEZZATO, A.C.; CARRIJO, A.S.; CALDARA, F.R.; OLIVEIRA, R.P. Studies on carbon-13 turnover in eggs and blood of commercial layers. Revista Brasileira de Ciência Avícola, v.8, p.251-256, 2006.

DENIRO, M.J.; EPSTEIN, S. Influence of diet on the distribution of nitrogen isotopes in animals. Geochimica et Cosmichimica Acta, v.42, p.495-506, 1981.

GOMES, J.P.C. Biossegurança x Rastreabilidade. In: SIMPÓSIO DE SANIDADE AVÍCOLA DA UFSM, 5, 2006, Santa Maria. Anais. Santa Maria: Universidade Federal de Santa Maria, 2006. p.100-104.

GONZÁLEZ-MARTIN, I.; GONZÁLEZ-PÉREZ, C.; HERNÁNDEZ-MÉNDEZ, J.; MARQUÉS-MACIAS, E.; SANZPOVEDA, F. Use of isotope analysis to characterize meat from Iberian-breed swine. Meat Science, v.52, p.437-441, 1999.

GONZÁLEZ-MARTIN, I.; GONZÁLEZ-PÉREZ, C.; HERNÁNDEZ-MÉNDEZ， J.; SÁNCHEZ GONZÁLEZ， C. Differentiation of dietary regimen of Iberian swine by means of isotopic analysis of carbon and sulphur in hepatic tissue. Meat Science, v.58, p.25-30, 2001.

GOTTMANN, R.; PEZZATO, A.C.; DUCATTI, C.; DENADAI, J.C.; MÓRI, C.; MITUO, M.A.O.; SARTORI, J.R. Rastreabilidade de subprodutos de origem animal em dietas com levedura e trigo para frangos. Pesquisa Agropecuária Brasileira, v.43, p.16411647, 2008.

HANDLEY, L.L.; RAVEN, J.A. The use of natural abundance of nitrogen isotopes in plant physiology and ecology. Plant Cell and Environment, v.15, p.965-985, 1992.

KOZIET, J.; ROSSMANN, A.; MARTIN, G.J.; ASHURST, P.R. Determination of carbon-13 content of sugars of fruit and vegetable juices. Analytica Chimica Acta, v.271, p.31-38, 1993.

LICATTI, F. Isótopos estáveis do carbono $\left({ }^{13} \mathrm{C} /{ }^{12} \mathrm{C}\right)$ em plantas do ciclo bioquímico $\mathbf{C}_{3}$ e $\mathbf{C}_{4}$. 1997. 65p. Monografia (Bacharelado) - Universidade Estadual Paulista, Botucatu.

MANCA, G.; CAMIN, F.; COLORU, G.; DEL CARO, A.; DETENTORI, D.; FRANCO, M.A.; VERSINI, G. Characterisation of the geographical origin of Pecorino sardo cheese by casein stable isotope $\left({ }^{13} \mathrm{C} /{ }^{12} \mathrm{C}\right.$ and $\left.{ }^{15} \mathrm{~N} /{ }^{14} \mathrm{~N}\right)$ ratios and free amino acid ratios. Journal of Agricultural and Food Chemistry, v.49, p.1404-1409, 2001.

MARTIN, G.J.; GUILLOU, C.; MARTIN, M.L.; CABANIS, M.T.; TEP, X.; AERNY, J. Natural factors of isotope fractionation and the characterization of wines. Journal of Agricultural and Food Chemistry, v.36, p.316-322, 1988.
MÓRI, C.; GARCIA, E.A.; DUCATTI, C.; DENADAI, J.C.; PELÍCIA, K.; GOTTMANN, R.; MITUO, M.A.O.; BORDINHON, A.M. Traceability of animal byproducts in quail (Coturnix coturnix japonica) tissues using carbon $\left({ }^{13} \mathrm{C} /{ }^{12} \mathrm{C}\right)$ and nitrogen $\left({ }^{15} \mathrm{~N} /{ }^{14} \mathrm{~N}\right)$ stable isotopes. Revista Brasileira de Ciência Avícola, v.9, p.263-269, 2007.

OLIVEIRA, R.P. Rastreabilidade da farinha de vísceras de aves na alimentação de frangos de corte pela técnica dos isótopos estáveis $\left(\delta^{13} \mathbf{C} \mathbf{e} \delta^{15} \mathbf{N}\right) .2005 .109$ p. Tese (Doutorado) - Universidade Estadual Paulista, Botucatu.

PIASENTIER, E.; VALUSSO, R.; CAMIN, F.; VERSINI, G. Stable isotope ratio analysis for authentication of lamb meat. Meat Science, v.64, p.239-247, 2003.

ROSA, C.R.; MORAES, M.; GOMES NETO, J.A.; NOBREGA, J.A.; NOGUEIRA, A.R. Effect of modifiers on thermal behavior of Se in acid digestates and slurry of vegetables by graphite furnace atomic absorption spectrometry. Food Chemistry, v.79, p.517-523, 2002.

ROSSMANN, A.; HABERHAUER, G.; HOLZL, S.; HORN, P.; PICHLMAYER, F.; VOERKELIUS, S. The potential of multielement stable isotope analysis for regional origin assignment of butter. European Food Research \& Technology, v.211, p.3240, 2000.

ROSTAGNO, H.S.; ALBINO, L.F.T.; DONZELE, J.L.; GOMES, P.C.; FERREIRA, A.S.; OLIVEIRA, R.F.; LOPES, D.C.; BARRETO, S.L.T. Tabelas brasileiras para aves e suínos: Composição de alimentos e exigências nutricionais. Viçosa: Universidade Federal de Viçosa, 2005. 186p.

SAS INSTITUTE. SAS user's guide. Version 6.11. 4.ed. Cary: SAS Institute, 1996. v.2. 842p.

TIESZEN, L.L.; BOUTTON, T.W.; TESDAHL, K.G.; SLADE, N.A. Fractionation and turnover of stable carbon isotopes in animal tissues: implications for $\delta^{13} \mathrm{C}$ analysis of diet. Oecologia, v.57, p.32-37, 1983.

UBA - União Brasileira de Avicultura. Relatório Anual 2007/2008. Disponível em: <http://www.uba.org.br/uba_rel08_internet.pdf $>$. Acesso em: 27 nov. 2008.

VOGEL, J.C. Variability of carbon isotope fractionation during photosynthesis. In: EHLERINGER, J.R.; HALL, A.E.; FARQUHAR, G.D. (Ed.). Stable isotopes and plant carbonwater relations. San Diego: Academic Press, 1993. p.29-46.

WERNER, R.A.; SCHIMIDT, H.L. The in vivo nitrogen isotope discrimination among organic plant compounds. Phytochemistry, v.61, p.465-784, 2002.

WHITE, J.W.; WINTERS, K.; MARTIN, P.; ROSSMANN, A. Stable carbon isotope ratio analysis of honey: validation of internal standard procedure for worldwide application. Journal of the Association of Official Analytical Chemists International, v.81, p.610-619, 1998.

Recebido em 21 de agosto de 2008 e aprovado em 19 de dezembro de 2008 